\title{
TECTONOPHYSICAL MEETINGS IN THE USSR AND RUSSIA: INFORMATION ON THE EVE OF THE THIRD TECTONOPHYSICAL CONFERENCE IN IPE RAS "TECTONOPHYSICS AND TOPICAL PROBLEMS IN EARTH SCIENCES” (MOSCOW, 8-12 OCTOBER 2012)
}

\author{
Yu. L. Rebetsky ${ }^{1}$, M. A. Goncharov, Yu. O. Kuz’min ${ }^{1}$, K. Zh. Seminsky ${ }^{3}$, S. I. Sherman ${ }^{3}$ \\ ${ }^{1}$ Schmidt Institute of Physics of the Earth, RAS, Moscow, Russia \\ ${ }^{2}$ Lomonosov Moscow State University, Moscow, Russia \\ ${ }^{3}$ Institute of the Earth's Crust, SB RAS, Irkutsk, Russia
}

\begin{abstract}
The article provides a brief review of the history of tectonophysical meetings in the former Soviet Union and Russia. This information is published on the eve of the Third Tectonophysical Conference convened by the Institute of Physics of the Earth in October 2012.
\end{abstract}

Key words: tectonophysics, conference.

Recommended by E.V. Sklyarov 22 August 2012

Citation: Rebetsky Yu.L., Goncharov M.A., Kuz’min Yu.O., Seminsky K.Zh., Sherman S.I., 2012. Tectonophysical meetings in the USSR and Russia: Information on the eve of the Third Tectonophysical Conference in IPE RAS “Tectonophysics and Topical Problems in Earth Sciences” (Moscow, 8-12 October 2012). Geodynamics \& Tectonophysics 3 (3), 309-314. doi:10.5800/GT-2012-3-3-0076.

\section{ТЕКТОНОФИЗИЧЕСКИЕ СОВЕЩАНИЯ В СССР И РОССИИ: ИНФОРМАЦИЯ НАКАНУНЕ ТРЕТЬЕЙ ТЕКТОНОФИЗИЧЕСКОЙ КОНФЕРЕНЦИИ В ИФЗ РАН “ТЕКТОНОФИЗИКА И АКТУАЛЬНЫЕ ВОПРОСЫ НАУК О ЗЕМЛЕ” (МОСКВА, 8-12 ОКТЯБРЯ 2012 Г.)}

\author{
Ю. Л. Ребецкий ${ }^{1}$, М. А. Гончаров ${ }^{2}$, Ю. О. Кузьмин ${ }^{1}$, К. Ж. Семинский ${ }^{3}$, С. И. Шерман ${ }^{3}$ \\ ${ }^{1}$ Институт физики Земли им. О.Ю. Шмидта РАН, Москва, Россия \\ ${ }^{2}$ Московский государственный университет им. М.В. Ломоносова, Москва, Россия \\ ${ }^{3}$ Институт земной коры СО РАН, Иркутск, Россия
}

\begin{abstract}
Аннотация: В статье представлен краткий обзор истории проведения тектонофизических совещаний в бывшем СССР и России. Эта информация публикуется в преддверии Третьей тектонофизической конференции, организуемой в Институте физики Земли РАН в октябре 2012 г.
\end{abstract}


История проведения тектонофизических конференций в Институте физики Земли РАН и в России в целом начинается с 1957 г. В тот год в ИФЗ РАН (тогда Геофизический институт АН СССР) под руководством Владимира Владимировича Белоусова и Михаила Владимировича Гзовского прошло Первое Всесоюзное тектонофизическое совещание. Основным координатором совещания являлась тектонофизическая группа под руководством М.В. Гзовского, которая тогда находилась в отделе геодинамики Геофизического института Академии наук СССР (ГЕОФИАН). Позднее, в 1968 г., эта группа была преобразована в лабораторию тектонофизики.

После завершения совещания был подготовлен и издан сборник трудов «Проблемы тектонофизики» (М.: Наука, 1960. 250 с.), в котором были опубликованы статьи известных советских ученых (Г.Д. Ажгирей, В.В. Белоусов, М.П. Воларович, М.В. Гзовский, В.И. Кейлис-Борок, П.Н. Кропоткин, Е.А. Кузнецов, Н.И. Николаев, А.В. Пэк, П.А. Ребиндер, Я.Б. Фридман, Л.Е. Эйгельсон).

Совещание 1957 г. дало мощный толчок развитию тектонофизики в СССР. В различных научных институтах стали создаваться группы и лаборатории, основными задачами которых становится использование методов тектонофизики при проведении исследований. Кроме лаборатории тектонофизики, организованной в 1953 г. в Московском государственном университете под руководством В.В. Белоусова (в настоящее время рук. М.А. Гончаров), аналогичные коллективы создаются и в других научных учреждениях: в Институте физики Земли (1968 г.) в г. Москве под руководством М.В. Гзовского (в настоящее время рук. Ю.Л. Ребецкий), в Институте земной коры (1979 г.) в г. Иркутске под руководством С.И. Шермана (в настоящее время рук. К.Ж. Семинский), в Институте геофизики НАН Украины в г. Киеве под руководством В.Г. Гутермана (в настоящее время рук. Я.И. Хазан), в Институте геологии и геофизики в г. Новосибирске под руководством И.В. Лучицкого.

Кроме этих крупных тектонофизических центров, возникли также небольшие группы, появились отдельные исследователи, использовавшие в своей научной деятельности тектонофизические методы. Сюда можно отнести, прежде всего, группу физического эксперимента структур в масштабе литосферы (моделирование областей субдукции и рифтинга) под руководством А.И. Шеменды в Геологическом музее МГУ (г. Москва); группу А.В. Лукьянова в Геологическом институте РАН, использовавшую в своих исследованиях методы структурной геологии и аналогового моделирования и обобщавшую результаты своих исследований в контексте тектонофизических задач; А.Н. Бокуна, занимавшегося в Геофизическом институте в г. Львове моделированием на глинистых пастах; группу геологов в Геологическом институте г. Ташкента (Ш.Д. Фатхуллаев, Р.А. Умурзаков); группу геологов под руково- дством Е.И. Паталахи, развивавшую в Геологическом институте Казахской АН (г. Алма-Ата) полевые методы изучения деформационных структур и некоторые элементы их структурного анализа.

Совещание 1957 г., став первым всесоюзным тектонофизическим совещанием в СССР, долгие годы было единственным, в котором рассматривался широкий спектр тектонофизических проблем. Главными темами совещания были: «Физические основы тектонофизики», «Мелкие тектонические нарушения и петротектоника», «Крупные тектонические нарушения и складкообразование», «Моделирование тектонических нарушений». Практически все последующие научные симпозиумы посвящались отдельным важным проблемам тектонофизики. Ниже мы приводим перечень большого числа совещаний и конференций, в которых в той или иной мере звучала тектонофизическая тематика.

В 1964 г. в ИГЕМ (г. Москва) под руководством чл.-корр. АН СССР Г.Д. Афанасьева прошел научный симпозиум «Физико-механические свойства горных пород верхней части земной коры», а в 1965 г. в г. Алма-Ате под руководством председателя НС по физикотехническим проблемам разработки полезных ископаемых АН СССР Н.В. Мельникова и Ж.С Ержанова прошла большая конференция «Механика горных пород». В 1969 г. в г. Киеве проводился научный симпозиум «Проблемы реологии горных пород и релаксации в твердых телах».

В 1970 г. в г. Москве состоялся совместный семинар сотрудников Московского горного института и лаборатории тектонофизики ИФЗ АН СССР, связанный с обсуждением проблем изучения природных напряжений на основе in-situ методов, развиваемых в горном деле. Руководителями семинара были М.В. Гзовский и Д.М. Казикаев. В семидесятые годы прошлого века в Институте горного дела г. Новосибирска начинают проводиться семинары и конференции по изучению природных напряжений комплексом методов in-situ. Активное участие в проведении этих конференций вплоть до настоящего времени (очередная конференция прошла в 2012 г.) принимал А.В. Леонтьев. В последние годы в ИГД СО РАН регулярно проводятся конференции «Геодинамика и напряженное состояние недр Земли» под руководством чл.-корр. РАН В.Н. Опарина. Тема изучения природных напряжений и механизмов их генерации является одной из приоритетных. В 1971 г. на Украине в г. Днепропетровске состоялся семинар «Вопросы теоретической и экспериментальной реологии горных пород», проведенный Институтом геотехнической механики АН УССР, а в 1974 г. в г. Ленинграде прошла научная конференция «Механика литосферы (исследование механики геологических тел для геологического прогнозирования и управления горным давлением)». В 1980 г. в г. Апатиты под руководством чл.-корр. АН СССР И.А. Турчанинова прошла Всесоюзная школа-семинар «Измерение напряжений и их приложение в прогнозе земле- 
трясений».

Серия симпозиумов была организована секцией «Экспериментальная тектоника и структурная геология» Междуведомственного тектонического комитета. В 1982 г. в г. Новосибирске под руководством И.В. Лучицкого, П.М. Бондаренко и В.И. Громина (Институт геологии и геофизики СО АН СССР, г. Новосибирск) прошел 1-й Всесоюзный симпозиум «Экспериментальная тектоника в решении задач теоретической и практической геологии». В 1987 г. в г. Ялта (Украина) под руководством В.Г. Гутермана и О.Б. Гинтова был проведен 2-й Всесоюзный симпозиум «Экспериментальная тектоника в решении задач теоретической и практической геологии». В 1992 г. в г. Москве под руководством А.В. Лукьянова, П.М. Бондаренко и М.А. Гончарова в МГУ прошел 3-й Всесоюзный симпозиум «Механизмы структурообразования в литосфере и сейсмичность». В 1997 г. под руководством А.В. Лукьянова и М.А. Гончарова в ГИН РАН был проведен 4-й Всесоюзный симпозиум «Структурные парагенезы и их ансамбли».

В 1991 г. в г. Киеве в Геофизическом институте им. С.И. Субботина прошла конференция «Экспериментальная тектоника и полевая тектонофизика», а в 1994 г. в г. Москве под руководством О.Л. Кузнецова во ВНИИГеосистем проводился международный семинар «Напряжения в литосфере (глобальные, региональные, локальные)».

Серия всесоюзных и международных совещаний по изучению современных движений земной коры под руководством Ю.Д. Буланже в 70-х и 80-х годах прошлого века была проведена в различных городах СССР. На этих совещаниях ключевыми являлись вопросы тектонофизической интерпретации современных движений.

Большой вклад в проведение научных конференций с тематикой, прямо отвечающей тектонофизической направленности, внес ИЗК СО РАН (г. Иркутск). На базе созданной в 1979 г. С.И. Шерманом лаборатории тектонофизики была организована серия совещаний со следующими тематиками: «Количественный анализ геологических явлений» (1988 г.); «Тектонофизические аспекты разломообразования в литосфере» (1991 г.); «Напряженное состояние литосферы, ее деформации и сейсмичность» (2003 г.); «Разломообразование и сейсмичность в литосфере: тектонофизические концепции и следствия» (2009 г.). Эти регулярно проводимые тектонофизические совещания характеризовались постоянной направленностью на исследование процессов разломообразования под углом зрения меры и числа, поиском новых концепций в изучении деструкции литосферы и синхронно протекающих процессов. Последний из перечисленных научных форумов отличался широким спектром тематик тектонофизического профиля, в обсуждении которых приняли участие 160 специалистов. Было представлено 215 тезисов докладов, в том числе от ученых дальнего и ближнего зарубежья (Англия, Китай, Франция, Сирия, Украина, Узбекистан и др.). Работало два круглых стола, где состоялись открытые свободные дискуссии по определяющим проблемам тематики совещания. Сибирское отделение было представлено шестью институтами, среди которых лидировали Институт земной коры СО PAН, Институт нефтегазовой геологии и геофизики СО РАН, Институт геологии и минералогии СО РАН и Институт физики прочности и материаловедения СО РАН. Был проведен анализ и обмен мнениями о состоянии и современных проблемах исследования процессов разломообразования и сейсмичности в литосфере, сделаны оригинальные подходы к выработке принципиально новых концепций изучения этих процессов на уровне возможностей XXI в. В этом плане иркутские совещания, безусловно, способствовали координации тектонофизических исследований, проводимых в научных учреждениях РФ, ряде зарубежных научных центров. Они убедительно показали, что тектонофизика как наука оказалась той современной отраслью исследований, которая по широте и методической базе успешно справляется с решением сложных теоретических и практических задач геологии и геофизики. Работа по подготовке очередного тектонофизического совещания по разломной тематике в ИЗК СО РАН продолжается.

По ряду причин в ИФЗ РАН после Первого тектонофизического совещания долгие годы тектонофизические конференции не проводились. В связи с юбилеем лаборатории тектонофизики ИФЗ РАН с 13 по 17 октября 2008 г. в ИФЗ РАН была проведена Всероссийская тектонофизическая конференция «Тектонофизика и актуальные вопросы наук о Земле. К 40-летию создания М.В. Гзовским лаборатории тектонофизики в ИФ3 РАН» (http://tph_2008.ifz.ru). На этой конференции вновь, как и на Первом тектонофизическом совещании, был рассмотрен широкий спектр проблем тектонофизики. Темами конференции были: «Теоретические вопросы тектонофизики», «Тектонофизическое моделирование деформационных структур», «Изучение природных напряжений и деформаций», «Разлом как особое геологическое и физическое тело», «Тектонофизика в решении проблем поиска и разработки месторождений полезных ископаемых», «Региональная тектоника, геофизические и сейсмологические данные».

В работе конференции приняли участие около 200 ученых, приехавших из двадцати шести городов нашей страны, а также ученые из тринадцати стран ближнего и дальнего зарубежья. Тезисы конференции, выпущенные до ее начала, представили информацию о 233 докладах. По результатам работы конференции было принято решение о необходимости регулярного, раз в четыре года, проведения в ИФЗ РАН подобных конференций. Было также предложено в период между конференциями проводить молодежные тектонофизические школы-семинары с привлечением на них в каче- 
стве лекторов ведущих ученых.

В соответствии с решениями конференции 2008 г., в ИФЗ РАН в 2009 и 2011 гг. проводились молодежные школы-семинары (http://tph_2009.ifz.ru, http://tph_2011.ifz.ru), на которые приезжало около 35-40 молодых исследователей из России и стран СНГ. На этих молодежных школах, кроме докладов самих молодых ученых, заслушивались также доклады и лекции ведущих ученых России.

В 2012 г., в соответствии с решением тектонофизической конференции, в ИФЗ РАН 2008 г. начата подготовка к проведению следующей тектонофизической конференции. Сделанный выше исторический обзор тектонофизических конференций в бывшем СССР и в современной России, а также рассмотренных на них тем позволяет говорить о правопреемственности проведенной в 2008 г. тектонофизической конференции в ИФЗ РАН и готовящейся конференции 2012 г. Первому всесоюзному тектонофизическому совещанию. В этой связи мы приняли решение именовать эту конфе- ренцию как «Третью тектонофизическую конференцию в ИФЗ РАН». Эта конференция проводится по патронажем Совета по проблемам тектоники и геодинамики при ОНЗ РАН (рук. академик Ю.Г. Леонов), в котором в настоящее время создана секция тектонофизики под руководством д. физ.-мат. н. Ю.Л. Ребецкого. С 8 по 12 октября 2012 г. в г. Москве будет проводиться Третья тектонофизическая конференция в ИФЗ РАН «Тектонофизика и актуальные вопросы наук о Земле».

Конференция позиционируется как всероссийская с привлечением исследователей из бывших республик СССР. Информация о конференции была разослана в начале года по всем научным центрам России и ближнего зарубежья, и с 1 марта 2012 г. на сайте http://agora.guru.ru/display.php?conf=tph_2012 происходила регистрация заявок на участие в ней. Текущая информация об участниках конференции размещена на сайте ИФЗ РАН http://tph_2012.ifz.ru.

Оркомитетом конференции получено 267 заявок на участие в конференции, и уже представлено 216 тези-

География участия в конференции

The geography of participation in the conference

\begin{tabular}{|c|c|c|c|}
\hline Города & Страны & Участники & Доклады \\
\hline Алмата & Казахстан & 1 & 1 \\
\hline Апатиты & Россия & 10 & 7 \\
\hline Архангельск & Россия & 1 & 1 \\
\hline Бишкек & Кыргыстан & 8 & 6 \\
\hline Борок & Россия & 2 & 1 \\
\hline Владивосток & Россия & 3 & 3 \\
\hline Донецк & Украина & 1 & 2 \\
\hline Душанбе & Таджикистан & 4 & 2 \\
\hline Екатеринбург & Россия & 6 & 5 \\
\hline Иркутск & Россия & 22 & 18 \\
\hline Казань & Россия & 1 & 1 \\
\hline Калининград & Россия & 1 & 1 \\
\hline Киев & Украина & 7 & 5 \\
\hline Краснодар & Россия & 4 & 2 \\
\hline Красноярск & Россия & 1 & 2 \\
\hline Львов & Украина & 7 & 8 \\
\hline Магадан & Россия & 1 & 1 \\
\hline Махачкала & Россия & 3 & 1 \\
\hline Москва & Россия & 93 & 87 \\
\hline Нерюнгри & Россия & 1 & 2 \\
\hline Новосибирск & Россия & 21 & 16 \\
\hline Обнинск & Россия & 2 & 2 \\
\hline Петропавловск-Камчатский & Россия & 5 & 4 \\
\hline Пермь & Россия & 2 & 2 \\
\hline Петрозаводск & Россия & 3 & 3 \\
\hline Санкт-Петербург & Россия & 8 & 9 \\
\hline Сыктывкар & Россия & 1 & 1 \\
\hline Ташкент & Узбекистан & 18 & 8 \\
\hline Тбилиси & Грузия & 1 & 1 \\
\hline Томск & Россия & 12 & 9 \\
\hline Тюмень & Россия & 1 & 1 \\
\hline Улан-Удэ & Россия & 2 & 3 \\
\hline Уфа & Россия & 2 & 1 \\
\hline Южно-Сахалинск & Россия & 7 & 5 \\
\hline Якутск & Россия & 2 & 0 \\
\hline
\end{tabular}


сов докладов (см. http://tph_2012.ifz.ru). В таблице показаны города и страны участников конференции по состоянию на 1 июля 2012 г.

Основными темами конференции являются:

1. Современная геодинамика, природные напряжения земной коры и механизмы их генерации.

2. Процессы течения горных масс и механизмы неустойчивости верхних слоев тектоносферы.

3. Зонно-блоковая структура литосферы и разломы коры.

4. Вопросы геомеханики и тектонофизического моделирования напряженно-деформированного состояния коры и литосферы.

5. Тектонофизика в приложении к проблемам горного дела, безопасности крупных промышленных объектов и оценки сейсмической опасности.

Краткий обзор проведенных за прошедшие 55 лет целенаправленных тектонофизических совещаний, а также конференций с докладами на тектонофизические темы свидетельствует о постепенно расширяющемся применении тектонофизических методов исследований в науках о Земле. Хорошо прослеживаемая тенденция находит отражение и в готовящейся третьей тектонофизической конференции, которая будет проведена в ИФЗ РАН. Это свидетельствует о расширении точных методов анализа при возможности применения цифровых характеристик для описания геологических процессов и тектонических структур, поиска математических связей между структурами и внутри них, а также влияния физических закономерностей в пространственно-временном эволюционном геодинамическом процессе.

Оргкомитет конференции приглашает ученых, заинтересованных в обсуждении методических и региональных тектонофизических проблем, принять участие в конференции в качестве докладчиков и слушателей.

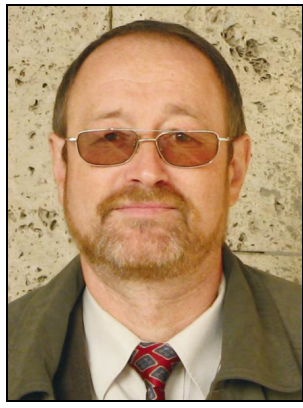

Ребецкий Юрий Леонидович, докт. физ.-мат. наук, зав. лабораторией тектонофизики им. М.В. Гзовского Институт физики Земли им. О.Ю. Шмидта РАН

123995, ГСП-5, Москва Д-242, ул. Большая Грузинская, 10, Россия

Тел.: 849925493050; $₫$ e-mail: reb@ifz.ru

Rebetsky, Yuri L., Doctor of Physics and Mathematics, Head of M.V. Gzovsky Laboratory of Tectonophysics Schmidt Institute of Physics of the Earth, RAS

10 Bol'shaya Gruzinskaya street, Moscow D-242 123995, GSP-5, Russia

Tel.: 849925493050; $\bowtie$ e-mail: reb@ifz.ru

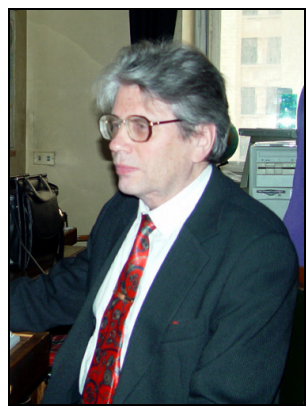

Гончаров Михаил Адрианович, докт. геол.-мин. наук,

зав. лабораторией тектонофизики и геотектоники им. В.В. Белоусова

Московский государственный университет им. М.В. Ломоносова, геологический факультет

119991, ГСП-1, Москва, Ленинские горы, Россия

Тел.: (495)9391912; e-mail: m.a.gonch@mail.ru

Goncharov, Mikhail A., Doctor of Geology and Mineralogy,

Head of V.V. Belousov Laboratory of Tectonophysics and Geotectonics

Lomonosov Moscow State University, Geological Faculty

Leninskie Gory, Moscow 119991, GSP-1, Russia

Tel.: (495)9391912; e-mail: m.a.gonch@mail.ru

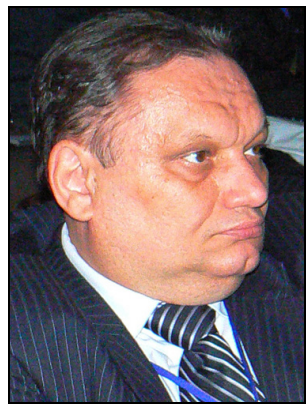

Кузьмин Юрий Олегович, докт. физ.-мат. наук, профессор, зав. лабораторией современной геодинамики Институт физики Земли им. О.Ю. Шмидта РАН

123995, ГСП-5, Москва Д-242, ул. Большая Грузинская, 10, Россия

Тел.: (495)2549135; e-mail: kuzpnex@gmail.com

Kuz'min, Yuri O., Doctor of Physics and Mathematics, Professor, Head of Laboratory of Recent Geodynamics Schmidt Institute of Earth Physics, RAS

10 Bol'shaya Gruzinskaya street, Moscow D-242 123995,GSP-5, Russia

Tel.: (495)2549135; e-mail: kuzpnex@gmail.com 

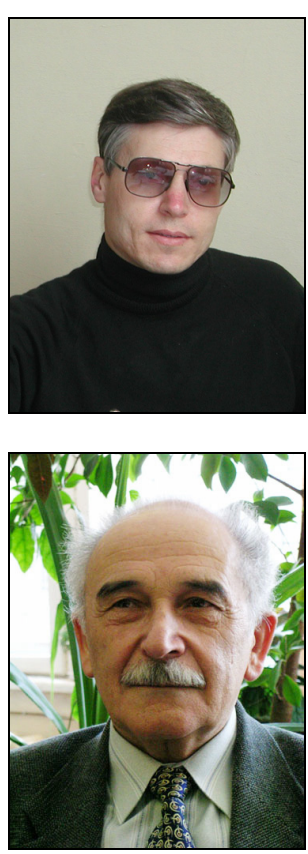

Семинский Константин Жанович, докт. геол.-мин. наук, зав. лабораторией тектонофизики Институт земной коры СО РАН

664033, Иркутск, ул. Лермонтова, 128, Россия

Тел.: (3952)423027; e-mail: seminsky@crust.irk.ru

Seminsky, Konstantin Zh., Doctor of Geology and Mineralogy, Head of Laboratory of Tectonophysics Institute of the Earth's Crust, SB RAS

128 Lermontov street, Irkutsk 664033, Russia

Tel.: (3952)423027; e-mail: seminsky@crust.irk.ru

Шерман Семен Иойнович, академик Российской академии естественных наук, докт. геол.-мин. наук, профессор, г.н.с.

Институт земной коры СО РАН

664033, Иркутск, ул. Лермонтова, 128, Россия

Тел.: (3952)428261; e-mail: ssherman@crust.irk.ru

Sherman, Semen I., Academician of the Russian Academy of Natural Sciences,

Doctor of Geology and Mineralogy, Professor, Chief Researcher

Institute of the Earth's Crust, SB RAS

128 Lermontov street, Irkutsk 664033, Russia

Tel.: (3952)428261; e-mail: ssherman@crust.irk.ru 